\title{
Acute high-altitude sickness
}

\author{
Andrew M. Luks ${ }^{1}$, Erik R. Swenson ${ }^{1,2}$ and Peter Bärtsch ${ }^{3}$ \\ Number 5 in the Series "Sports-related lung disease" \\ Edited by Yochai Adir and Alfred A. Bove
}

\begin{abstract}
Affiliations: ${ }^{1}$ Dept of Medicine, Division of Pulmonary and Critical Care Medicine, University of Washington, Seattle, WA, USA. ${ }^{2}$ Medical Service, Veterans Affairs Puget Sound Health Care System, Seattle, WA, USA. ${ }^{3}$ Dept of Internal Medicine, University Clinic Heidelberg, Heidelberg, Germany.
\end{abstract}

Correspondence: Andrew M. Luks, Division of Pulmonary and Critical Care Medicine, Harborview Medical Center, 325 Ninth Avenue, Box 359762, Seattle, WA 98104, USA. E-mail: aluksdu.washington.edu

@ERSpublications

Lack of acclimatisation is the main risk factor for acute altitude illness; descent is the optimal treatment http://ow.ly/45d2305JyZ0

Cite this article as: Luks AM, Swenson ER, Bärtsch P. Acute high-altitude sickness. Eur Respir Rev 2017; 26: 160096 [https://doi.org/10.1183/16000617.0096-2016].

ABSTRACT At any point $1-5$ days following ascent to altitudes $\geqslant 2500 \mathrm{~m}$, individuals are at risk of developing one of three forms of acute altitude illness: acute mountain sickness, a syndrome of nonspecific symptoms including headache, lassitude, dizziness and nausea; high-altitude cerebral oedema, a potentially fatal illness characterised by ataxia, decreased consciousness and characteristic changes on magnetic resonance imaging; and high-altitude pulmonary oedema, a noncardiogenic form of pulmonary oedema resulting from excessive hypoxic pulmonary vasoconstriction which can be fatal if not recognised and treated promptly. This review provides detailed information about each of these important clinical entities. After reviewing the clinical features, epidemiology and current understanding of the pathophysiology of each disorder, we describe the current pharmacological and nonpharmacological approaches to the prevention and treatment of these diseases.

\section{Introduction}

Large numbers of people are ascending to high altitudes for the purposes of pleasure, work and athletic competition. Among other important changes, such as decreases in temperature and ambient humidity, the defining environmental feature at high altitude is a drop in barometric pressure, which causes a decrease in the partial pressure of oxygen at every point along the oxygen transport cascade from ambient air to cellular mitochondria. This hypobaric hypoxia triggers a series of physiological responses, which, in most cases, help the individual tolerate and adapt to the low oxygen conditions. However, in other cases, maladaptive responses occur, that in turn cause one of three forms of acute altitude illness, acute mountain sickness (AMS), high-altitude cerebral oedema (HACE) and high-altitude pulmonary oedema (HAPE). These diseases can develop at any time from several hours to 5 days following ascent to a given

Previous articles in this series: No. 1: Adir Y, Bove AA. Can asthmatic subjects dive? Eur Respir Rev 2016; 25: 214-220. No. 2: Szpilman D, Orlowski JP. Sports related to drowning. Eur Respir Rev 2016; 25: 348-359. No. 3: van Ooij PJAM, Sterk PJ, van Hulst RA. Oxygen, the lung and the diver: friends and foes? Eur Respir Rev 2016; 25: 496-505. No. 4: Mijacika T, Dujic Z. Sport-related lung injury during breath-hold diving. Eur Respir Rev 2016; 25: 506-512.

Received: Sept 132016 | Accepted after revision: Oct 232016

Conflict of interests: None declared.

Provenance: Submitted article, peer reviewed.

Copyright CERS 2017. ERR articles are open access and distributed under the terms of the Creative Commons Attribution Non-Commercial Licence 4.0. 
elevation and can range in severity from mild with minimal effect on the planned travel itinerary to life-threatening illness.

The review is intended to provide detailed information about each of these entities. For each disease, we review the clinical features, epidemiology and the current understanding of their pathophysiology. We then review the primary pharmacological and nonpharmacological approaches to the management of each form of acute altitude illness and provide practical recommendations for both prevention and treatment. For the purposes of this review, we will consider high altitude as elevations $\geqslant 2500 \mathrm{~m}$, although it should be recognised that the physiological responses to hypobaric hypoxia start at lower elevations, and thus some individuals who are highly susceptible to acute altitude illness may become sick at altitudes $<2500 \mathrm{~m}$.

\section{AMS and HACE \\ Clinical aspects}

AMS consists of nonspecific symptoms that occur at altitudes of $\geqslant 2500 \mathrm{~m}$ in unacclimatised individuals with a usual delay of $4-12 \mathrm{~h}$ after arrival at a new altitude. The symptoms are usually most pronounced after the first night spent at a new altitude and resolve spontaneously when appropriate measures are taken [1]. The leading symptom is headache, which is required for the diagnosis of AMS by the most frequently used scoring system [2]. However, this has been questioned by those who argue, based on anecdotal reports, that some individuals (probably 5\% [3]) with symptoms clearly attributable to high altitude will be missed by having headache as a compulsory symptom. [4] Additional symptoms are loss of appetite or nausea, dizziness, fatigue or lassitude and insomnia. These are all nonspecific, and insomnia, in particular, is very prevalent in healthy individuals at high altitude. Progression of symptoms including nausea and headache not responding to first-line antiemetics and analgesics and increasing lassitude may point to progression of AMS to HACE [5]. The leading signs of HACE are truncal ataxia and clouded consciousness. Absence of preceding or concurrent headache does not exclude the diagnosis of HACE [6]. Without appropriate treatment, HACE usually leads to death, sometimes within $24 \mathrm{~h}$ of onset.

Clinical and routine laboratory examinations do not reveal abnormal findings in AMS. Usually, arterial oxygen saturation $\left(\mathrm{SaO}_{2}\right)$ and tension $\left(\mathrm{PaO}_{2}\right)$ are on average slightly lower compared to healthy controls at a given altitude, and the alveolar-arterial oxygen tension difference slightly greater (table 1). However, there is a large overlap of individual values [7] and statistically significant differences can only be obtained in studies of large groups. These blood gas changes might be due to a mild interstitial oedema not visible on chest radiographs [8], but suggested by a slight decrease of vital capacity and increase of closing volume $[9,10]$; however, these are inconsistent findings [11]. Furthermore, a lower ventilatory drive in hypoxia might contribute to more severe hypoxaemia in AMS, at least in some individuals $[12,13]$. Laboratory investigations of the brain in AMS show that all subjects exposed to altitudes of $4500 \mathrm{~m}$ had normal lumbar cerebrospinal fluid pressure and a small increase of brain volume assessed using MRI $(<1 \%, \sim 7-$ $10 \mathrm{~mL}$ ) after $16 \mathrm{~h}$, independent of presence or absence of AMS [14]. The volume increase can partly be attributed to increased blood volume and partly to cell swelling [14, 15]. A recent study demonstrated swelling of white matter correlating with AMS scores after $22 \mathrm{~h} \mathrm{[16].}$

The clinical hallmarks of HACE are truncal ataxia and decreased consciousness, which can rapidly progress to coma without appropriate treatment, as discussed in the last section of this review. $\mathrm{SaO}_{2}$ and $\mathrm{PaO}_{2}$ are usually considerably lower than in AMS, even without signs of pulmonary oedema, which will eventually develop when HACE worsens [17]. Laboratory investigations show increased lumbar cerebrospinal fluid pressure [18]. Brain MRI performed at low altitude immediately after rescue by

TABLE 1 Arterial blood gas analysis at $4559 \mathrm{~m}$

\begin{tabular}{lclcc} 
& Subjects & $\mathrm{PaO}_{2} \mathbf{~} \mathbf{m m g}$ & $\mathrm{PacO}_{2} \mathbf{m m H g}$ & ${\mathrm{PA}-\mathrm{aO}_{2} \mathbf{m m H g}} \mathbf{m m}$ \\
\hline No AMS & 14 & $39.6 \pm 4.5$ & $30.0 \pm 3.6$ & $7.9 \pm 3.7$ \\
Mild AMS & 19 & $37.6 \pm 4.3$ & $30.7 \pm 4.0$ & $9.3 \pm 4.3$ \\
Moderate-severe AMS & 10 & $33.9 \pm 4.0^{*}$ & $31.1 \pm 2.8$ & $12.5 \pm 4.5^{*}$ \\
HAPE & 4 & $23.2 \pm 3.3^{* * *}$ & $28.4 \pm 3.5$ & $26.0 \pm 2.9^{* * *}$
\end{tabular}

Analysis of arterial blood obtained from a femoral artery a few hours after arrival at the Margherita hut (Monte Rosa, Italy) in subjects with no acute mountain sickness (AMS), mild AMS (score 2-3 points according to HACKETT et al. [103]), moderate-to-severe AMS (>3 points) or high-altitude pulmonary oedema (HAPE) (verified using chest radiography). $\mathrm{PaO}_{2}$ : arterial oxygen tension; $\mathrm{PaCO}_{2}$ : arterial carbon dioxide tension; $P \mathrm{~A}_{-\mathrm{aO}} \mathrm{O}_{2}$ : alveolar-arterial oxygen tension difference. ${ }^{*}: \mathrm{p}<0.05$, compared with mild and no AMS; ***: $p<0.001$, compared with all groups. Data from [32]. 
helicopter showed oedema in the corpus callosum [19]. Susceptibility-weighted MRI demonstrated a leak of the blood-brain barrier for erythrocytes as evidenced by hemosiderin deposition persisting over years in the corpus callosum and throughout the brain in more severe cases after HACE (figure 1) [20].

The differential diagnosis of AMS and HACE includes exhaustion, hypothermia, hyponatraemia, migraine, dehydration, infection, carbon monoxide poisoning, drug and alcohol intoxication, hypoglycaemia or severe hyperglycaemia, transient ischaemic attack or stroke and acute psychosis, possibly related to intake of corticosteroids [21].

\section{Epidemiology}

There is no systematic analysis of risk factors for HACE, due to the rarity of the disease. Since AMS may progress to HACE, risk factors for AMS are also relevant for HACE, as avoiding AMS will prevent HACE.

The major determinants of AMS are the altitude attained [22], individual susceptibility, rate of ascent and degree of preacclimatisation $[13,23,24]$. Therefore, prevalence of AMS depends very much on the study setting. Prevalence of AMS varies between $40 \%$ and $90 \%$, depending on altitude and individual susceptibility in unacclimatised individuals ascending considerably more than $500 \mathrm{~m} \cdot \mathrm{day}^{-1}$ to altitudes of $4500-6000 \mathrm{~m}$ $[23,25]$, whereas prevalence with passive ascent to $3000-3500 \mathrm{~m}$ is $\sim 25-40 \%[26,27]$. HACE occurs rarely at altitudes $<4000 \mathrm{~m}$, and its prevalence between $4200 \mathrm{~m}$ and $5500 \mathrm{~m}$ is estimated to be $0.5-1 \%$ [17].

A low ventilatory drive in hypoxia [13, 27, 28] and history of migraine [13] are minor risk factors, while smoking and alcohol intake do not increase the risk of AMS. Aside from some limited evidence regarding lung disease [27] and obesity [27, 28], there is no evidence that the presence of underlying medical problems such as asthma, coronary artery disease or diabetes mellitus increase the risk of becoming ill following ascent. Susceptibility to AMS is not different between males and females, while children and adolescents are possibly less prone to AMS [26]. People aged $>40-60$ years tend to develop AMS less than younger adults [27]. Recent studies examining the hypothesis that exercise enhances AMS yielded controversial results [29-31].

\section{Pathophysiology}

We still lack a unified, coherent explanation for the development of AMS and HACE. Multiple factors have been implicated, as follows.

\section{Hypoxaemia}

Most studies measuring oxygenation in AMS find that $\mathrm{SaO}_{2}$ or $\mathrm{PaO}_{2}$ are lower in AMS versus non-AMS groups with a large interindividual overlap [32] (table 1). A lower ventilatory drive in hypoxia [7, 13], impaired gas exchange due to interstitial pulmonary oedema [10] and fluid retention [7] or increased metabolism [1] may contribute to slightly more pronounced hypoxaemia in AMS.

Consequences of more severe hypoxaemia in AMS might involve a greater increase in cerebral blood flow (CBF). CBF measured by transcranial Doppler in AMS yielded controversial results, possibly because of changes in the diameter of the middle cerebral artery that was assumed to remain unchanged [33]. However,
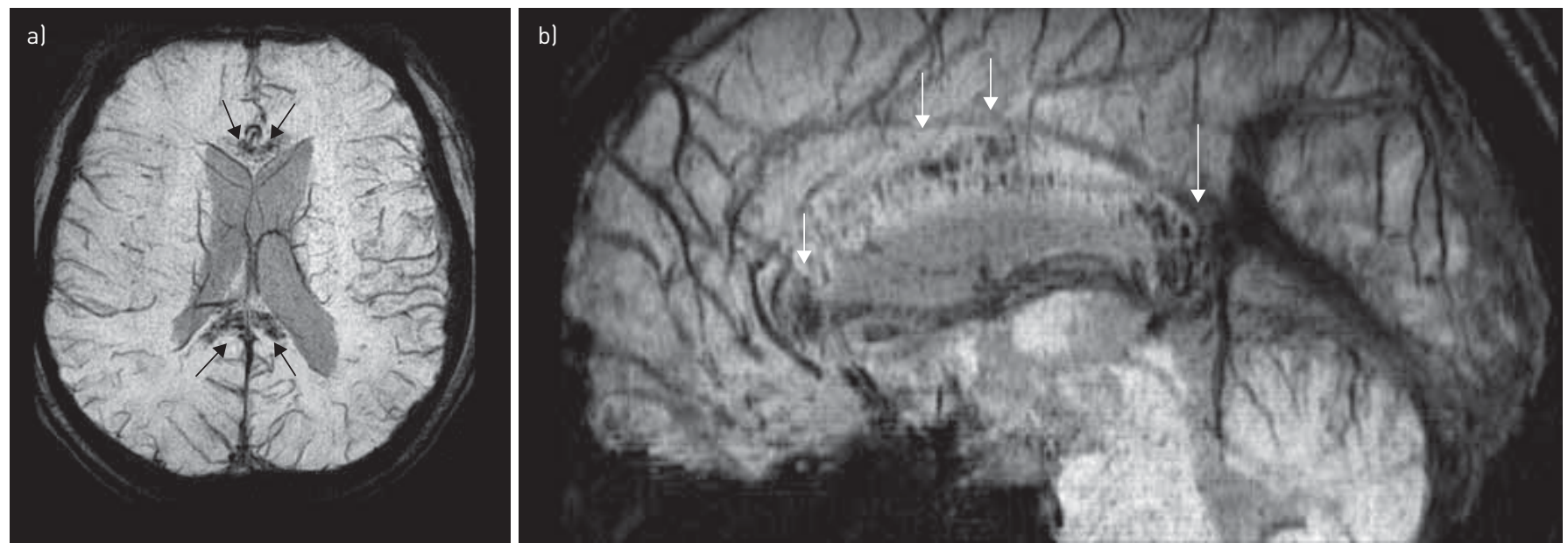

FIGURE 1 Susceptibility-weighted magnetic resonance imaging in a) axial and b) sagittal planes shows microhaemorrhages (arrows) in the corpus callosum of a 65-year-old female who had suffered from severe high-altitude cerebral oedema 7 weeks previously at $3450 \mathrm{~m}$. Reproduced from [1] with permission from the publisher. 
changes in the diameter of the internal carotid artery did not correlate with high-altitude headache [34]. Thus it is not clear at present whether differences in CBF are present between those with and without AMS.

A further consequence of more severe hypoxaemia could be an increase in vascular permeability through a higher oxidative stress [35], low-grade inflammation [36] or increased hypoxia-inducible transcription factor-dependent expression of vascular endothelial growth factor (VEGF), which might be involved in the pathophysiology of HACE as suggested by animal experiments [37]. However, in AMS, lumbar punctures reveal an intact blood-brain barrier for large molecular weight proteins [38]. Furthermore, there are no significant associations of peripheral oedema [39], slight increase in brain volume [14], albuminuria [40] and leakage of fluorescent dye from retinal vessels [41] with AMS. Thus, the slight tissue swelling in the body in hypoxia is not different between those with and without AMS.

The brain

Headache is the primary symptom of AMS. Pain perception occurs only in the large blood vessels and meninges though sensory fibres of the trigeminal ganglia that project to the cortex. Connections of these afferent fibres to vegetative centres in the brainstem can explain accompanying symptoms such as nausea and vomiting [42]. Potential mechanisms of activation of these pain receptors in AMS are pressure or distortion through brain swelling or increased intracerebral pressure (ICP), vascular distension due to increased intravascular pressure or release of nociceptive chemicals/substances.

Most MRI studies in AMS found volume changes of $<10 \mathrm{~mL}$ between 6 and $16 \mathrm{~h}$ of hypoxia with no correlation to AMS symptom scores [43]. These studies could not distinguish between oedema and changes in blood volume, but most of them found decreased water mobility compatible with intracellular swelling associated with AMS. A recent sequential MRI study over $22 \mathrm{~h}$ showed that increased inflow into the brain preceded formation of white matter oedema $(13 \mathrm{~mL})$, which correlated with a cumulative AMS score over $22 \mathrm{~h}$ [16]. Taken together, these studies indicate that AMS is accompanied by a mild intracellular oedema predominantly in the white matter that is unlikely to account directly for irritation of cerebral pain receptors.

Direct measurements indicate that ICP appears to be normal in subjects with AMS at rest [38, 44], but may increase with exercise or other factors that increase blood or intrathoracic pressure [45], due to decreased intracranial compliance. Disturbed autoregulation may occur in AMS [35, 46] and could enhance pressure transduction to the brain, although findings are controversial [47]. Repeated transient increases of ICP may sensitise trigeminal nociception [48] and decrease compliance of the CNS to a variable degree, since the capacity for spatial compensation varies considerably between individuals [49].

Venous outflow restriction due to anatomical variations of the sinus transversus leading to cerebral vein congestion was suggested to play a role in the pathophysiology of AMS [50]. However, the correlation between headache scores during trekking and retinal vein congestion at $5300 \mathrm{~m}$ reported in support of this hypothesis could not be confirmed in a more standardised setting at $4500 \mathrm{~m}$ [51]. In a recent article, those authors show that parenchymal swelling compresses small veins and hence also contributes to venous outflow restriction [16]. The concept of interindividual variability of venous outflow restriction contributing to AMS could explain the lack of consistent correlations between AMS and factors relevant for cerebral inflow, such as CBF, ventilator responses to hypoxia (HVR) or $\mathrm{SaO}_{2}$. It also fits with the observations that AMS worsens overnight or with bending over and improves after getting up and when CBF decreases with acclimatisation.

Thus, susceptibility to AMS appears to be determined by an interaction of physiological responses to hypoxia (ventilation, cerebral vasculature, autonomic nervous system and nociceptive thresholds) and anatomical factors such as the compensatory capacity for cerebrospinal fluid and the capacity of venous outflow. The mechanisms involved in the pathophysiology of AMS may also lead to HACE, which can be considered end-stage AMS. Longer duration of illness, development of worsened oxygenation with HAPE and greater hypoxic stress may account for progression. HACE is characterised by increased ICP, visually detectable oedema on MRI and a blood-brain barrier leak with hemosiderin deposition in the brain. VEGF is probably one of the major contributors to the severe vasogenic oedema leading to HACE, as suggested by animal experiments [37].

\section{HAPE}

Clinical aspects

HAPE occurs in healthy individuals at altitudes $>2500-3000 \mathrm{~m}$ within 1-5 days after arrival [52]. It is rarely observed below these altitudes and after 1 week of acclimatisation. In many cases it is preceded by symptoms of AMS. Early symptoms include excessive exertional dyspnoea in relation to the patient's companions, mild cough, chest tightness and reduced exercise performance. As oedema progresses, cough and dyspnoea worsen and orthopnoea develops. Gurgling in the chest and pink frothy sputum indicate advanced cases. 
Examination reveals cyanosis, tachypnoea, tachycardia, mildly elevated temperature and crackles upon auscultation. As $\mathrm{SaO}_{2}$ plummets, signs of hypoxic encephalopathy or, in some cases, HACE may develop. Arterial blood gas and $\mathrm{SaO}_{2}$ measurements in advanced HAPE at $4559 \mathrm{~m}$ demonstrate its severity: mean $\mathrm{PaO}_{2}$ registered in the mid- $20 \mathrm{mmHg}$ range versus $35-45 \mathrm{mmHg}$ in healthy controls, and $\mathrm{SaO}_{2}$ measurements were $<50 \%$ versus $70-85 \%$ (table 1) [53]. Chest radiographs and computed tomography scans in symptomatic HAPE (figure 2) show a patchy peripheral and nodular distribution of oedema [54]. Bronchoalveolar lavage (BAL) shows a protein-rich exudate and mild alveolar haemorrhage, which initially is noninflammatory, but may progress after several days to a more inflammatory picture, as discussed later [55-57]. Echocardiographic and pulmonary artery catheterisation studies at high altitude show marked pulmonary hypertension [58-60].

\section{Epidemiology}

Two populations are affected by HAPE. The first involves well-acclimatised alpine residents returning from low altitudes (re-entry HAPE) and the second involves rapid ascent of unacclimatised lowlanders. Altitude, ascent rate and individual susceptibility are the major determinants of HAPE. Its prevalence ranges from $<0.2 \%$ in a general mountaineering population when climbing in $\geqslant 3$ days to altitudes of $4000-5000 \mathrm{~m}$, but as high as $7 \%$ with a single-day ascent. A similar increase in HAPE incidence of $2.5 \%$ versus $15.5 \%$ occurs when an altitude of $5500 \mathrm{~m}$ is reached by trekking over 4-6 days as opposed to airlift. In those with a history of radiographically documented HAPE, the likelihood of developing HAPE is $60 \%$ with a 1-2-day ascent to the same altitude $[52,53]$.

\section{Pathophysiology}

The pathophysiology of HAPE has been reviewed extensively elsewhere [61]. Since its recognition in the 1960s, a number of pathophysiological mechanisms have been proposed. It was clear early on that pulmonary hypertension and HAPE were inextricably linked, suggesting a primary haemodynamic basis. However, it is clear that some individuals with strong hypoxic pulmonary vasoconstriction (HPV) do not develop HAPE [62]. Thus, other factors may be necessary contributors to HAPE susceptibility. Studies suggestive of an inflammatory pathogenesis, reduced or defective active sodium and water reabsorption by the hypoxic alveolar epithelium and unevenness of regional HPV have been advanced as possibilities for how HAPE may develop.

\section{Haemodynamics}

Right heart catheterisation at high altitude revealed mean (range) pulmonary artery pressures of 60 (35-115) mmHg, but normal pulmonary artery wedge pressures [58-60]. These pioneering studies put to rest the idea that HAPE was acute left heart failure at high altitude. Excessive pulmonary artery pressures precede the development of HAPE and are not a consequence of the disease [63]. The critical role of high pulmonary artery pressure is further confirmed by the fact that descent, oxygen or drugs that lower pulmonary artery pressure are effective for prevention and treatment as discussed below.
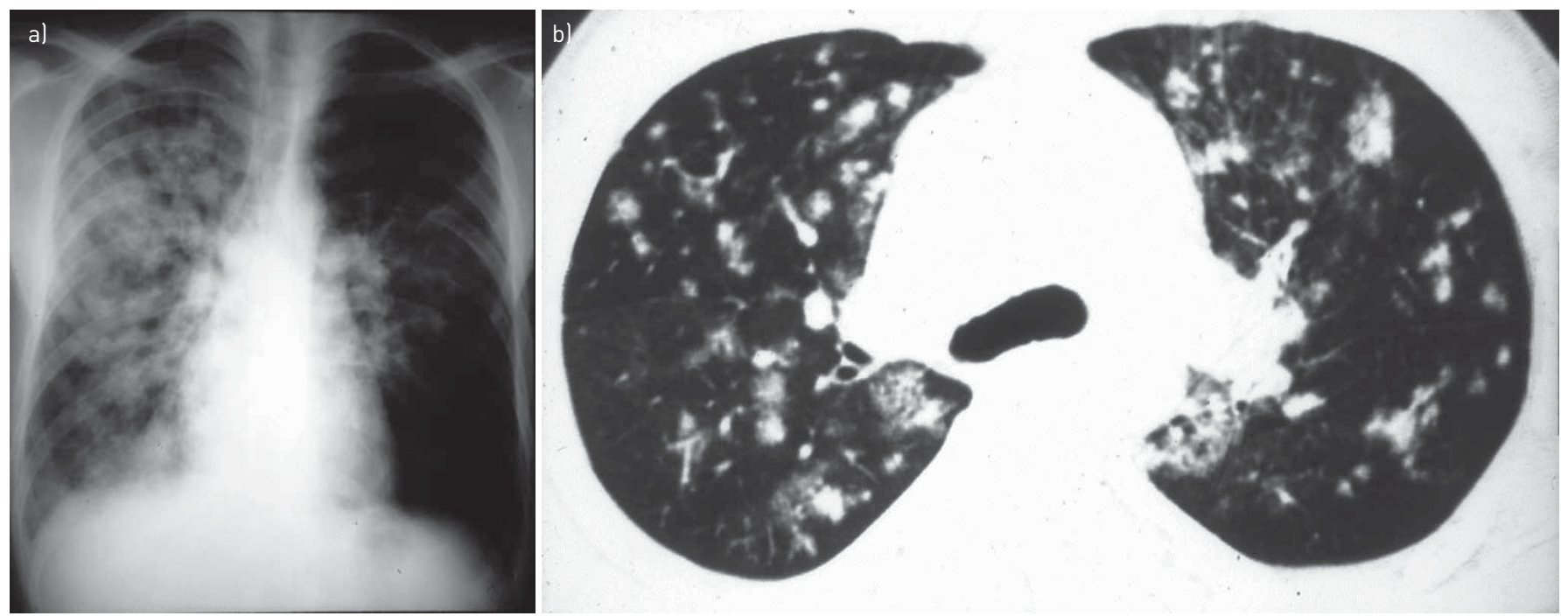

FIGURE 2 a) Chest radiograph of a 37-year-old male mountaineer with high-altitude pulmonary oedema (HAPE) showing a patchy to confluent distribution of oedema, predominantly on the right side; b) computed axial tomography scan of 27-year-old mountaineer with recurrent HAPE showing patchy bilateral nodular distribution of oedema. Reproduced from [61] with permission from the publisher. 
Individuals susceptible to HAPE have many physiological characteristics that place them at greater risk. The most important is a strong HPV response, as well as higher pressures with even normoxic exercise $[64,65]$. The exaggerated rise in pulmonary artery pressure in susceptible individuals developing HAPE is accompanied by increased microvascular pressure $>20 \mathrm{mmHg}$, a threshold pressure for formation of alveolar oedema $[59,66]$.

The basis for high hypoxic pulmonary artery pressures in HAPE-susceptible subjects is multifactorial. They have lower HVR [12, 67] and stronger sympathetic tone [68]. HVR is set largely by the peripheral chemoreceptors, which results in a lower alveolar oxygen tension and higher carbon dioxide tension at the same altitude as HAPE-resistant subjects, and thus leads to a stronger stimulus for HPV [69]. Increased peripheral hypoxic chemoreceptor sensitivity also appears to reduce the strength of HPV, independent of differences in alveolar ventilation [70]. HAPE-susceptible individuals have slightly lower lung volumes and reduced diffusion capacity $[12,71,72]$.

In addition, there are differences in the vasculature. Nitric oxide (NO) and endothelin-1 are important pulmonary endothelial-derived vasodilator and vasoconstrictor mediators. Endothelin production is greater in HAPE susceptibility [73], while lung NO production is reduced [56, 74, 75]. Systemic vascular endothelial NO generation is reduced more in hypoxic HAPE-susceptible subjects compared to controls [76]. This is probably also the case for the pulmonary circulation, as the above-cited measurements of exhaled NO and metabolites of NO in lavage fluid suggest.

The question arises how hypoxic constriction of pulmonary vessels leads to oedema. Three mechanisms have been suggested [53]: 1) transarteriolar leakage with oedema occurring upstream of the microvasculature at small weaker arteriolar right-angle branches off larger pulmonary arteries; 2) heterogeneous regional arterial hypoxic vasoconstriction; and 3) hypoxic venoconstriction. If arterial vasoconstriction in hypoxia is inhomogeneous, HAPE could be the consequence of higher flows in those areas with lesser vasoconstriction, leading to increased microvascular pressure. MRI of lung blood flow demonstrates that HPV is uneven at rest in susceptible individuals [77, 78], but not in those with proven HAPE resistance. This unevenness in regional HPV may help to explain the characteristic patchy and nodular appearance of oedema in HAPE.

The reason(s) why the pulmonary vasculature leaks under high pressure are not completely resolved. Traditionally, pulmonary oedema has been categorised as either noncardiogenic (increased permeability with exudative characteristics: high protein concentrations and markers of inflammation in the setting of normal or only modestly elevated intravascular pressures) or cardiogenic (elevated hydrostatic pressures leading to a noninflammatory protein-poor transudative leak). As described above, BAL fluid in nascent HAPE [56] reveals characteristics of a hydrostatic, but noncardiogenic noninflammatory oedema suggesting pressure-induced alterations to the normal permeability of the alveolar-capillary barrier or frank traumatic injury; the latter has been termed capillary stress failure [79].

If hydrostatic forces persist, then gene upregulation and transcription of collagen and other extracellular matrix proteins are initiated to strengthen the alveolar capillary barrier [80] and ultimately reduce stress failure and leak. These observations offer an explanation for the rapid recovery from HAPE and the protection from recurrence when re-ascending only several days after recovery from HAPE.

\section{Inflammation}

The first measurements of alveolar lavage fluid in mountaineers [55, 57] were obtained in those with established HAPE. In addition to the high protein concentrations, some, but not all cases had significant neutrophilia and elevations of pro-inflammatory cytokines and neutrophil chemotactic factors. These observations strongly suggested that inflammation might be a causal factor in HAPE, leading to a greater permeability of the lung microvasculature. However, not all cases of HAPE had evidence of inflammation [55], indicating that in humans inflammation is possibly a secondary response to alveolar-capillary barrier disruption or oedema. BAL in HAPE-susceptible climbers showed mild alveolar haemorrhage and increased serum-derived protein concentrations within a day of ascent to $4559 \mathrm{~m}$ from low altitude both in subjects ill with HAPE at the time of bronchoscopy and in those who developed HAPE in the next $24 \mathrm{~h}$ [56]. There is a strong correlation between the magnitude of pulmonary hypertension assessed by echocardiography and the degree of haemorrhage and protein elevation in the alveolar space (figure 3). In contrast, there were no increases in alveolar macrophages, neutrophils and pro-inflammatory mediators at high altitude early in the course of HAPE.

It is not clear what initiates the secondary inflammation. It may be that sustained and increasing high pressures of sufficient duration in untreated HAPE can trigger inflammation [81], or it represents part of the healing process of a markedly disrupted alveolar-capillary barrier that occurs in the most severe cases of HAPE, especially with alveolar haemorrhage, since haem and other breakdown products of red cell 

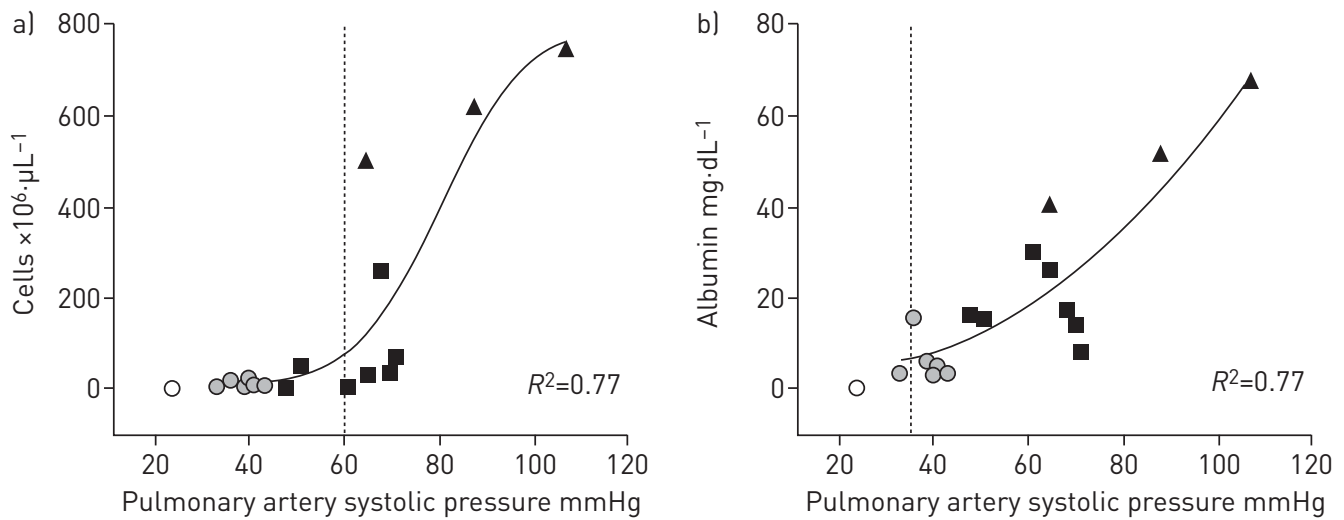

FIGURE 3 Individual bronchoalveolar lavage a) red blood cell counts and b) albumin concentrations plotted against pulmonary artery systolic pressures at high altitude $(4559 \mathrm{~m})$. Reproduced from [56] with permission from the publisher.

haemoglobin are chemotactic for neutrophils [82]. Despite overwhelming evidence against a primary inflammatory alteration of the alveolar-capillary barrier in HAPE, it is nevertheless conceivable that any concurrent process altering the permeability of the alveolar-capillary barrier will lower the pressure required for formation of oedema. Indeed, increased fluid accumulation during hypoxic exposure after priming by endotoxin or virus in animals $[83,84]$ and the association of preceding respiratory viral infections with HAPE in children $[85,86]$ support this concept. Thus, upper respiratory tract infections shortly before a sojourn in the mountains and vigorous exercise at altitudes between 2000 and $3000 \mathrm{~m}$ may explain in some cases why HAPE can develop at a modestly low altitude [87].

\section{Alveolar fluid clearance}

Disruption of the alveolar capillary barrier and leak are the proximal causes of HAPE, but studies have highlighted the possibility that alveolar fluid clearance mechanisms dependent upon active alveolar epithelial sodium and water reabsorption by type I and II pneumocytes may contribute to the pathophysiology of HAPE. Active fluid transport from the alveolar space into the lung interstitium and clearance via lymphatics is important in normal lung fluid balance. Hypoxia decreases transepithelial sodium transport by reducing expression and activity of the epithelial sodium channel (ENaC) and sodium $\left(\mathrm{Na}^{+}\right)$/potassium $\left(\mathrm{K}^{+}\right)$ATPase proteins [88], possibly by an impairment of $\beta_{2}$-adrenergic receptor signalling [89]. In vivo hypoxia depresses alveolar fluid clearance in hypoxic animals [90, 91]. Mice partially deficient in $\mathrm{ENaC}$ develop greater accumulation of lung water in hypoxia [92].

Another approach to study the relevance of alveolar transepithelial fluid reabsorption in HAPE has involved the use of $\beta_{2}$-receptor agonists and glucocorticoids, both of which upregulate $\mathrm{ENaC}$ and $\mathrm{Na}^{+} / \mathrm{K}^{+}$ ATPase [93]. Two field studies reported successful prevention of HAPE in HAPE-susceptible climbers with inhalation of salmeterol, a long-acting $\beta_{2}$-agonist [94], and oral dexamethasone [95] begun 1 day before ascent. Owing to multiple actions of $\beta_{2}$-adrenergic agonists, such as inhibition of HPV, increased HVR and ventilation, tightening of cell-to-cell contacts and upregulation of NO production [96], the contribution of enhanced alveolar fluid clearance remains uncertain. Indeed, the protective effect of dexamethasone from a putative enhancement of alveolar fluid reabsorption could not be correlated with indirect measures of enhanced active sodium reabsorption, but rather to a surprising reduction of pulmonary artery pressure [95].

\section{Prevention of acute altitude illness}

Depending on the circumstances of the planned ascent, prevention of acute altitude illness is based on a combination of various nonpharmacological and pharmacological approaches.

\section{Predicting who will get sick}

For the purpose of preventing acute altitude illness, it would be helpful to predict who is at risk of developing one of the three acute altitude illnesses. For an individual who has been to high altitude before, past performance is a good, but not perfect, predictor of future performance upon return to a similar altitude at a similar rate. For example, BÄrTsch et al. [97] have shown that $60 \%$ of HAPE-susceptible individuals develop HAPE on subsequent trips to high altitude. However, there remains no easy way to 
predict how the altitude-naïve traveller will fare following ascent. CANOUI-PoITRINe et al. [98] have developed and validated a model for identifying individuals at risk for severe altitude illness (severe AMS, HACE or HAPE), but the model requires an individual to undergo an exercise test while breathing a hypoxic gas mixture and, as a result, is not amenable to widespread, easy application. Furthermore, the value of such testing, which at present has not been validated by a prospective trial, was questioned in a recent pro [99] and con [100] debate.

\section{Nonpharmacological measures}

Slow ascent

Because overly rapid ascent remains the primary risk factor for developing acute altitude illness, undertaking a slow ascent to the target elevation remains the best method for altitude illness prevention. With ascents $>2500-3000 \mathrm{~m}$, individuals should not increase their sleeping elevation by $>300-600 \mathrm{~m}$ per night and should take a rest day every 3-4 days, in which they sleep at the same elevation for at least one additional night. This recommendation, the specifics of which vary slightly depending on the resource cited $[52,101,102]$, derives largely from observational data $[103,104]$ and has only been examined in a prospective, randomised manner in a single study [24]. Because local terrain and logistical factors often prevent adherence to these specific altitude limits on a day-by-day basis, individuals should instead focus on the ascent rate averaged over the entire trip [105]. Due to the significant interindividual variability in susceptibility to altitude illness, some individuals can tolerate faster ascent profiles than those prescribed above. People who travel repeatedly to high altitude learn more about their personal tolerances and can adjust their ascent rates accordingly and perhaps ascend at faster than recommended rates, while the individual with no prior experience in this environment should adhere to those limits specified above.

\section{Preacclimatisation}

Spending time at moderate altitude before ascending to the target elevation, described as "staged ascent", augments the beneficial physiological responses seen following ascent and decreases the incidence of acute altitude illness [106]. Studies have reported conflicting results regarding intermittent normobaric or hypobaric hypoxic exposures, with some studies showing benefit [107] and others not demonstrating a clear effect $[108,109]$. One of the challenges in interpreting these discrepant results is that the hypoxic exposure protocols vary significantly between studies with regard to the magnitude and duration of the hypoxic exposures. While these preacclimatisation strategies may carry benefit and probably pose little risk, implementation may be difficult for many travellers and the optimal approach remains unclear. Infrequent and/or short exposures to hypoxia are unlikely to reduce the incidence of AMS $[109,110]$, while longer and/or more frequent exposures are necessary to reduce the risk of altitude illness $[107,111]$. Such exposures should be performed as close in time to the planned high-altitude travel as possible. One particular preacclimatisation strategy that has received recent attention is sleeping at low elevation in an enclosed, oxygen-depleted space (e.g. a tent enclosing the bed) on a nightly basis. While anecdotal reports suggest that the use of such systems is increasing among climbers and other individuals travelling to high altitudes, the utility of this approach has not been examined extensively. DeHNERT et al. [112] conducted a randomised trial which demonstrated reduced symptoms and incidence of AMS with 14 consecutive nights of sleep in normobaric hypoxia, but reported technical difficulties maintaining the desired level of hypoxia on a consistent basis.

\section{Other measures}

Avoiding excessive alcohol consumption and opiate pain medications are other common-sense measures for preventing acute altitude illness, but which have not been studied in a systematic manner. Avoiding overexertion following ascent is another commonly recommended measure, although studies have reported varying results about the relationship between exertion and risk of AMS [29, 30, 113]. Abrupt cessation of caffeine intake in chronic users of caffeinated beverages may provoke withdrawal symptoms that mimic those of AMS [114]. The risk of dehydration is increased at high altitude due to the lower humidity in this environment and decrease in plasma volume following ascent, but dehydration has not been shown to increase the risk of AMS $[115,116]$. Fluid intake should be driven by thirst and sufficient to prevent dehydration and avoid continuously low and highly concentrated urine output, but systematic attempts to overhydrate should be avoided.

\section{Pharmacological measures}

A variety of medications can be used for the prevention of acute altitude illness (table 2). However, pharmacological prophylaxis is not necessary in all high-altitude travellers, and instead should be initiated based on an assessment of the risk of acute altitude illness associated with a planned trip that accounts for the individual's prior performance at high altitude, if known, and features of the planned ascent, such as the altitude reached on the first day, the number of planned rest days and the anticipated increase in 
TABLE 2 Medications for the prevention and treatment of acute altitude illness

Dosage for prevention

Dosage for treatment

$\begin{array}{lc}\text { AMS } & \\ \text { Acetazolamide } & 125 \text { or } 250 \mathrm{mg} \text { every } 12 \mathrm{~h} \\ \text { Dexamethasone } & 2 \mathrm{mg} \text { every } 6 \mathrm{~h} \text { or } \\ & 4 \mathrm{mg} \text { every } 12 \mathrm{~h} \\ \text { HAPE } & \\ \text { Nifedipine } & 30 \mathrm{mg} \text { sustained release } \\ & \text { version every } 12 \mathrm{~h} \\ \text { Tadalafil } & 10 \text { mg every } 12 \mathrm{~h} \\ \text { Salmeterol }^{\Uparrow 1} & 125 \mu \mathrm{g} \text { inhaled every } 12 \mathrm{~h}\end{array}$

$250 \mathrm{mg}$ every $12 \mathrm{~h}$

AMS: $4 \mathrm{mg}$ every $6 \mathrm{~h}$

HACE: $8 \mathrm{mg}$ once then $4 \mathrm{mg}$ every $6 \mathrm{~h}$

$30 \mathrm{mg}$ sustained release

version every $12 \mathrm{~h}$

$10 \mathrm{mg}$ every $12 \mathrm{~h}$

Not used for treatment

AMS: acute mountain sickness; HAPE: high-altitude pulmonary oedema; HACE: high-altitude cerebral oedema.

\#: should not be used in conjunction with nifedipine; " : should not be used as the sole agent for prevention.

sleeping elevation once $>2500-3000 \mathrm{~m}$ (table 3) [52, 102]. Pharmacological prophylaxis should be strongly considered for moderate-high-risk ascent profiles, but is not necessary in low-risk situations.

Pharmacological prophylaxis is largely directed toward the prevention of acute mountain sickness, which, as noted earlier, is by far the most common problem that affects people following ascent. At the same time, because HACE and HAPE are reflective of impaired acclimatisation, medications that prevent AMS theoretically reduce the risk of these entities as well, but this concept has not been studied in a systematic manner.

Acetazolamide remains the mainstay of AMS prophylaxis. While there has been debate about the appropriate dosage for prophylaxis [117], the bulk of the evidence suggests $125 \mathrm{mg}$ twice daily is sufficient for most climbs [102, 118], but may be inadequate for overly rapid ascents and/or ascents to very high final altitudes [119]. The medication is typically started the night before the planned ascent and continued until descent is initiated or until the individual has been at the target elevation for 2-3 days. Dexamethasone is a well-studied alternative $[120,121]$ for those who are intolerant of or have a contraindication to acetazolamide. Given the risk of adrenal suppression with long-term use of high-dose systemic corticosteroids, the medication should not be used for more than seven consecutive days and, if longer use is necessary, should be tapered off rather than stopped abruptly [21, 102].

Recent studies have suggested that ibuprofen at a dose of $1800 \mathrm{mg} \cdot \mathrm{day}^{-1}$ may be effective at preventing AMS [122], but studies have yet to establish superiority over acetazolamide or dexamethasone. In addition, safety with prolonged use at high altitude and, in particular the risk of gastrointestinal bleeding, remain unclear. Other recent studies have suggested that the inhaled steroid budesonide may have a role in AMS prophylaxis $[123,124]$. These studies raise important questions about lung involvement in the underlying pathophysiology of AMS [125], but have yet to be replicated and do not provide sufficient rationale for using this expensive medication in place of acetazolamide or dexamethasone.

TABLE 3 Risk assessment for acute altitude illness

Planned ascent profile and prior history at high altitude

Low risk

Moderate risk

High risk
Ascent $\leqslant 500 \mathrm{~m} \cdot$ day $^{-1}$ above $2500 \mathrm{~m}$
Ascent $>500 \mathrm{~m} \cdot$ day $^{-1}$ above $2500 \mathrm{~m}$ in persons with exposure to high altitude $<3000 \mathrm{~m}$ in preceding weeks

No history of AMS, HACE or HAPE with similar ascent profile Unknown susceptibility to AMS, HACE or HAPE and planned ascent $>500 \mathrm{~m} \cdot$ day $^{-1}$ above $3000 \mathrm{~m}$

Unknown susceptibility to acute altitude illness and planned ascent to $>3000 \mathrm{~m}$ in 1 day

Unknown susceptibility to AMS, HACE or HAPE and planned very rapid ascent ( $>500 \mathrm{~m} \cdot \mathrm{day}^{-1}$ ) to final altitude $>4000 \mathrm{~m}$

History of AMS, HACE and HAPE with previous exposure similar to the planned ascent

AMS: acute mountain sickness; HACE: high-altitude cerebral oedema; HAPE: high-altitude pulmonary oedema.

\# : altitudes refer to the individual's sleeping elevation. 
As noted in table 2, medications are available specifically for HAPE prophylaxis, but these are generally reserved for those with a prior history of HAPE. Based on a small, randomised trial [126] and extensive clinical experience, the pulmonary vasodilator nifedipine is the primary medication for this purpose. Other data demonstrate that the phosphodiesterase inhibitor tadalafil, dexamethasone [95] and the long-acting $\beta_{2}$-agonist salmeterol [94] are also effective at preventing HAPE in known susceptible individuals, although the latter agent is less effective than pulmonary vasodilators and may be considered only for use as an adjunct to other agents and not as the sole prophylactic option [102]. The dose is also substantially higher than that used for asthma treatment and can lead to tachycardia and tremulousness.

Individuals who are not familiar with the prophylactic medications should consider taking one or two doses prior to their planned travel to assess their tolerance of the medications and side-effect profile.

\section{Treatment}

While descent to lower elevation is the best treatment for all forms of acute altitude illness, the optimal approach varies based on the type and severity of illness and other factors.

\section{AMS}

The majority of patients who become ill at high altitude have AMS, which can typically be treated by stopping ascent and using nonsteroidal anti-inflammatory drugs acetaminophen or aspirin for headache and, in some cases, antiemetics for nausea. The utility of these drugs for treating the full spectrum of AMS symptoms has not been specifically examined, but they have been shown to be effective at treating high-altitude headache [127, 128]. Rehydration does not treat AMS per se, but does address any dehydration, the symptoms of which can mimic those of AMS. Acetazolamide [129] and dexamethasone $[121,130]$ can be added for those individuals with more severe AMS symptoms or those who fail to respond to conservative measures. Individuals who remain ill despite several days of these conservative measures should descend 500-1000 m or until symptoms resolve.

\section{HACE}

The onset of neurological symptoms suggestive of HACE is an indication for immediate descent. If not feasible due to weather, terrain or other logistical factors, ill individuals should be placed on supplemental oxygen via either an oxygen tank or oxygen concentrator or placed in a portable hyperbaric chamber [131]. Dexamethasone should be administered by the oral, intramuscular or intravenous route at a dose of $8 \mathrm{mg}$ initially followed by $4 \mathrm{mg}$ every $6 \mathrm{~h}$ until the person has descended or symptoms have fully resolved. [102] Diuretics are not part of the standard approach for HACE, nor is there any evidence or rationale for acetazolamide.

\section{HAPE}

The optimal approach to HAPE varies based on whether the individual is able to access care in a well-resourced setting [102, 132]. Fully conscious patients who can access health facilities in mountain resorts, for example, often do not need to descend, and instead can be managed with supplemental oxygen alone and close observation at either the health facility or their lodge. However, in more remote and/or under-resourced settings, HAPE patients should descend to lower elevation or, if not feasible, be treated with supplemental oxygen or a portable hyperbaric chamber as well as a pulmonary vasodilator. Based on a small, uncontrolled study [133], sustained-release nifedipine is the preferred agent for this purpose, while anecdotal reports suggest that phosphodiesterase- 5 inhibitors may be useful as well (table 2). Cases series describe concurrent use of pulmonary vasodilators, acetazolamide and inhaled $\beta_{2}$ agonists in HAPE treatment $[134,135]$, but there are no data to support this approach. While very early reports described their use in HAPE [136], diuretics are not part of standard protocols because many patients are volume depleted at the time of their illness, and diuretic administration increases the risk of hypotension. Use of continuous positive airway pressure without supplemental oxygen has also been described in several reports $[87,137]$, but has not been studied in a systematic manner.

\section{Re-ascent following resolution of acute altitude illness}

Individuals affected by AMS can resume their ascent once symptoms have resolved with careful attention to the rate of ascent and consideration of pharmacological prophylaxis. Although reports document successful ascents of Mount Everest following episodes of HAPE [138, 139], the safety of continuing ascent after resolution of HAPE or HACE remains controversial. If ascent is pursued in such circumstances, the individual should be symptom-free and off any medications for at least several days before initiating further ascent and should strongly consider pharmacological prophylaxis for their ascent, including a pulmonary vasodilator for individuals who had HAPE and dexamethasone for individuals who had HACE. 


\section{References}

1 Bartsch P, Bailey DM. Acute mountain sickness and high altitude cerebral oedema. In: Swenson ER, Bartsch P, eds. High Altitude Human Adaptation to Hypoxia. New York, Springer, 2014; pp. 379-404.

2 Roach RC, Bartsch P, Hackett PH, et al. The Lake Louise acute mountain sickness scoring system. In: Sutton JR, Coates G, Houston CS, eds. Hypoxia and Molecular Medicine: Proceedings of the 8th International Hypoxia Symposium, Lake Louise, Alberta, Canada. Burlington, Vt, Queen City Printers, 1993; pp. 272-274.

3 Sampson JB, Cymerman A, Burse RL, et al. Procedures for the measurement of acute mountain sickness. Aviat Space Environ Med 1983; 54: 1063-1073.

4 West JB. Con: headache should not be a required symptom for the diagnosis of acute mountain sickness. High Alt Med Biol 2011; 12: 23-25.

5 Wilson $\mathrm{MH}$, Newman S, Imray $\mathrm{CH}$. The cerebral effects of ascent to high altitudes. Lancet Neurol 2009; 8: $175-191$.

6 Wu T, Ding S, Liu J, et al. Ataxia: an early indicator in high altitude cerebral edema. High Alt Med Biol 2006; 7: 275-280.

7 Bärtsch P, Swenson ER, Paul A, et al. Hypoxic ventilatory response, ventilation, gas exchange, and fluid balance in acute mountain sickness. High Alt Med Biol 2002; 3: 361-376.

8 Vock P, Fretz C, Franciolli M, et al. High-altitude pulmonary edema: findings at high-altitude chest radiography and physical examination. Radiology 1989; 170: 661-666.

9 Cremona G, Asnaghi R, Baderna P, et al. Pulmonary extravascular fluid accumulation in recreational climbers: a prospective study. Lancet 2002; 359: 303-309.

10 Senn O, Clarenbach CF, Fischler M, et al. Do changes in lung function predict high-altitude pulmonary edema at an early stage? Med Sci Sports Exerc 2006; 38: 1565-1570.

11 Dehnert C, Luks AM, Schendler G, et al. No evidence for interstitial lung oedema by extensive pulmonary function testing at 4,559 m. Eur Respir J 2010; 35: 812-820.

12 Hohenhaus E, Paul A, McCullough RE, et al. Ventilatory and pulmonary vascular response to hypoxia and susceptibility to high altitude pulmonary oedema. Eur Respir J 1995; 8: 1825-1833.

13 Richalet JP, Larmignat P, Poitrine E, et al. Physiological risk factors for severe high-altitude illness: a prospective cohort study. Am J Respir Crit Care Med 2012; 185: 192-198.

14 Kallenberg K, Bailey DM, Christ S, et al. Magnetic resonance imaging evidence of cytotoxic cerebral edema in acute mountain sickness. J Cereb Blood Flow Metab 2007; 27: 1064-1071.

15 Schoonman GG, Sándor PS, Nirkko AC, et al. Hypoxia-induced acute mountain sickness is associated with intracellular cerebral edema: a 3 T magnetic resonance imaging study. J Cereb Blood Flow Metab 2008; 28: 198-206.

16 Sagoo RS, Hutchinson CE, Wright A, et al. Magnetic Resonance investigation into the mechanisms involved in the development of high-altitude cerebral edema. J Cereb Blood Flow Metab 2016; [In press DOI: 10.1177/ 0271678X15625350].

17 Bartsch P, Roach RC. Acute mountain sickness and high-altitude pulmonary edema. In: Hornbein TF, Schoene RB, eds. High Altitude: An Exploration in Human Adaptation. Lung Biology in Health and Disease. 161. New York, Marcel Dekker, 2001; pp. 731-776.

18 Singh I, Khanna PK, Srivastava MC, et al. Acute mountain sickness. N Engl J Med 1969; 280: 175-184.

19 Hackett PH, Yarnell PR, Hill R, et al. High-altitude cerebral edema evaluated with magnetic resonance imaging: clinical correlation and pathophysiology. JAMA 1998; 280: 1920-1925.

20 Schommer K, Kallenberg K, Lutz K, et al. Hemosiderin deposition in the brain as footprint of high-altitude cerebral edema. Neurology 2013; 81: 1776-1779.

21 Subedi BH, Pokharel J, Goodman TL, et al. Complications of steroid use on Mt. Everest. Wilderness Environ Med 2010; 21: 345-348.

22 Beidleman BA, Tighiouart $\mathrm{H}$, Schmid $\mathrm{CH}$, et al. Predictive models of acute mountain sickness after rapid ascent to various altitudes. Med Sci Sports Exerc 2013; 45: 792-800.

23 Schneider M, Bernasch D, Weymann J, et al. Acute mountain sickness: influence of susceptibility, preexposure, and ascent rate. Med Sci Sports Exerc 2002; 34: 1886-1891.

24 Bloch KE, Turk AJ, Maggiorini M, et al. Effect of ascent protocol on acute mountain sickness and success at Muztagh Ata, 7546 m. High Alt Med Biol 2009; 10: 25-32.

25 Kayser B, Dumont L, Lysakowski C, et al. Reappraisal of acetazolamide for the prevention of acute mountain sickness: A systematic review and meta-analysis. High Alt Med Biol 2012; 13: 82-92.

26 Kriemler S, Bürgi F, Wick C, et al. Prevalence of acute mountain sickness at $3500 \mathrm{~m}$ within and between families: a prospective cohort study. High Alt Med Biol 2014; 15: 28-38.

27 Honigman B, Theis MK, Koziol-McLain J, et al. Acute mountain sickness in a general tourist population at moderate altitudes. Ann Intern Med 1993; 118: 587-592.

28 Ri-Li G, Chase PJ, Witkowski S, et al. Obesity: associations with acute mountain sickness. Ann Intern Med 2003; 139: 253-257.

29 Schommer K, Hammer M, Hotz L, et al. Exercise intensity typical of mountain climbing does not exacerbate acute mountain sickness in normobaric hypoxia. J Appl Physiol 2012; 113: 1068-1074.

30 Rupp T, Jubeau M, Millet GY, et al. The effect of hypoxemia and exercise on acute mountain sickness symptoms. J Appl Physiol 2013; 114: 180-185.

31 DiPasquale DM, Strangman GE, Harris NS, et al. Hypoxia, hypobaria, and exercise duration affect acute mountain sickness. Aerosp Med Hum Perform 2015; 86: 614-619.

32 Bärtsch P, Waber U, Haeberli A, et al. Enhanced fibrin formation in high-altitude pulmonary edema. J Appl Physiol 1987; 63: 752-757.

33 Wilson $\mathrm{MH}$, Edsell ME, Davagnanam I, et al. Cerebral artery dilatation maintains cerebral oxygenation at extreme altitude and in acute hypoxia - an ultrasound and MRI study. J Cereb Blood Flow Metab 2011; 31: 2019-2029.

34 Reeves JT, Moore LG, McCullough RE, et al. Headache at high altitude is not related to internal carotid arterial blood velocity. J Appl Physiol 1985; 59: 909-915.

35 Bailey DM, Evans KA, James PE, et al. Altered free radical metabolism in acute mountain sickness: implications for dynamic cerebral autoregulation and blood-brain barrier function. J Physiol 2009; 587: 73-85. 
Bailey DM, Taudorf S, Berg RM, et al. Inflammatory "priming" predisposes to acute mountain sickness. In: Roach RC, Wagner PD, Hackett PH, eds. Hypoxia and the Circulation. Banff, Springer, 2007; p. 300.

Schoch HJ, Fischer S, Marti HH. Hypoxia-induced vascular endothelial growth factor expression causes vascular leakage in the brain. Brain 2002; 125: 2549-2557.

Bailey DM, Roukens R, Knauth M, et al. Free radical-mediated damage to barrier function is not associated with altered brain morphology in high-altitude headache. J Cereb Blood Flow Metab 2006; 26: 99-111.

Hackett PH, Rennie D. Rales, peripheral edema, retinal hemorrhage and acute mountain sickness. Am J Med 1979; 67: 214-218.

Lewis DM, Bradwell AR, Shore AC, et al. Capillary filtration coefficient and urinary albumin leak at altitude. Eur J Clin Invest 1997; 27: 64-68.

Willmann G, Fischer MD, Schatz A, et al. Retinal vessel leakage at high altitude. JAMA 2013; 309: 2210-2212.

Sanchez del Rio M, Moskowitz MA. High altitude headache - lessons from headaches at sea level. In: Roach RC, Wagner PD, Hackett PH, eds. Hypoxia: Into the Next Millenium. New York, Kluwer Academic/Plenum Publishers, 1999; pp. 145-153.

Willmann G, Gekeler F, Schommer K, et al. Update on high altitude cerebral edema including recent work on the eye. High Alt Med Biol 2014; 15: 112-122.

Wilson $\mathrm{MH}$, Milledge J. Direct measurement of intracranial pressure at high altitude and correlation of ventricular size with acute mountain sickness: Brian Cummins' results from the 1985 Kishtwar expedition. Neurosurgery 2008; 63: 970-974.

Hartig GS, Hackett PH. Cerebral spinal fluid pressure and cerebral blood velocity in acute mountain sickness. In: Sutton JR, Coates G, Houston CS, eds. Hypoxia and Mountain Medicine. New York, Pergamon Press, 1992; pp. 260-265.

Van Osta A, Moraine JJ, Mélot C, et al. Effects of high altitude exposure on cerebral hemodynamics in normal subjects. Stroke 2005; 36: 557-560.

Subudhi AW, Fan JL, Evero O, et al. AltitudeOmics: cerebral autoregulation during ascent, acclimatization, and re-exposure to high altitude and its relation with acute mountain sickness. J Appl Physiol 2014; 116: 724-729.

Lawley JS, Levine BD, Williams MA, et al. Cerebral spinal fluid dynamics: effect of hypoxia and implications for high-altitude illness. J Appl Physiol 2016; 120: 251-262.

Ross RT. The random nature of cerebral mountain sickness. Lancet 1985; 1: 990-991. syndromes of cerebral venous hypertension. High Alt Med Biol 2011; 12: 379-386.

Willmann G, Fischer MD, Schommer K, et al. Missing correlation of retinal vessel diameter with high-altitude headache. Ann Clin Transl Neurol 2014; 1: 59-63.

Bärtsch P, Swenson ER. Clinical practice: acute high-altitude illnesses. N Engl J Med 2013; 368: 2294-2302.

Swenson ER, Bärtsch P. High-altitude pulmonary edema. Compr Physiol 2012; 2: 2753-2773.

Vock P, Brutsche MH, Nanzer A, et al. Variable radiomorphologic data of high altitude pulmonary edema. Features from 60 patients. Chest 1991; 100: 1306-1311.

Schoene RB, Swenson ER, Pizzo CJJr, et al. The lung at high altitude: bronchoalveolar lavage in acute mountain sickness and pulmonary edema. J Appl Physiol 1988; 64: 2605-2613.

Swenson ER, Maggiorini M, Mongovin S, et al. Pathogenesis of high-altitude pulmonary edema: inflammation is not an etiologic factor. JAMA 2002; 287: 2228-2235.

Kubo K, Hanaoka M, Hayano T, et al. Inflammatory cytokines in BAL fluid and pulmonary hemodynamics in high-altitude pulmonary edema. Respir Physiol 1998; 111: 301-310.

Maggiorini M, Mélot C, Pierre S, et al. High-altitude pulmonary edema is initially caused by an increase in capillary pressure. Circulation 2001; 103: 2078-2083.

Hultgren HN, Lopez CE, Lundberg E, et al. Physiologic studies of pulmonary edema at high altitude. Circulation 1964; 29: 393-408.

Penaloza D, Sime F. Circulatory dynamics during high altitude pulmonary edema. Am J Cardiol 1969; 23: 369-378. Bärtsch P, Mairbäurl H, Maggiorini M, et al. Physiological aspects of high-altitude pulmonary edema. J Appl Physiol 2005; 98: 1101-1110.

Dehnert C, Mereles D, Greiner S, et al. Exaggerated hypoxic pulmonary vasoconstriction without susceptibility to high altitude pulmonary edema. High Alt Med Biol 2015; 16: 11-17.

Bartsch P, Maggiorini M, Ritter M, et al. Prevention of high-altitude pulmonary edema by nifedipine. $N$ Engl Med 1991; 325: 1284-1289.

Eldridge MW, Podolsky A, Richardson RS, et al. Pulmonary hemodynamic response to exercise in subjects with prior high-altitude pulmonary edema. J Appl Physiol 1996; 81: 911-921.

Grünig E, Weissmann S, Ehlken N, et al. Stress Doppler echocardiography in relatives of patients with idiopathic and familial pulmonary arterial hypertension: results of a multicenter European analysis of pulmonary artery pressure response to exercise and hypoxia. Circulation 2009; 119: 1747-1757.

Homik LA, Bshouty Z, Light RB, et al. Effect of alveolar hypoxia on pulmonary fluid filtration in in situ dog lungs. J Appl Physiol 1988; 65: 46-52.

Hackett $\mathrm{PH}$, Roach RC, Schoene RB, et al. Abnormal control of ventilation in high-altitude pulmonary edema. J Appl Physiol 1988; 64: 1268-1272.

Duplain H, Vollenweider L, Delabays A, et al. Augmented sympathetic activation during short-term hypoxia and high-altitude exposure in subjects susceptible to high-altitude pulmonary edema. Circulation 1999; 99: 1713-1718. Swenson ER. Hypoxic pulmonary vasoconstriction. High Alt Med Biol 2013; 14: 101-110.

Albert TJ, Swenson ER. Peripheral chemoreceptor responsiveness and hypoxic pulmonary vasoconstriction in humans. High Alt Med Biol 2014; 15: 15-20.

Podolsky A, Eldridge MW, Richardson RS, et al. Exercise-induced VA/Q inequality in subjects with prior high-altitude pulmonary edema. J Appl Physiol 1996; 81: 922-932.

Steinacker JM, Tobias P, Menhold E, et al. Lung diffusing capacity and exercise in subjects with previous high altitude pulmonary oedema. Eur Respir J 1998; 11: 643-650.

Sartori C, Vollenweider L, Löffler BM, et al. Exaggerated endothelin release in high-altitude pulmonary edema. Circulation 1999; 99: 2665-2668. 
Busch T, Bärtsch P, Pappert D, et al. Hypoxia decreases exhaled nitric oxide in mountaineers susceptible to high-altitude pulmonary edema. Am J Respir Crit Care Med 2001; 163: 368-373.

Duplain H, Sartori C, Lepori M, et al. Exhaled nitric oxide in high-altitude pulmonary edema: role in the regulation of pulmonary vascular tone and evidence for a role against inflammation. Am J Respir Crit Care Med 2000; 162: 221-224.

Berger MM, Hesse C, Dehnert C, et al. Hypoxia impairs systemic endothelial function in individuals prone to high-altitude pulmonary edema. Am J Respir Crit Care Med 2005; 172: 763-767.

pulmonary edema. Am J Respir Crit Care Med 2005; 171: 83-87.

Dehnert C, Risse F, Ley S, et al. Magnetic resonance imaging of uneven pulmonary perfusion in hypoxia in humans. Am J Respir Crit Care Med 2006; 174: 1132-1138.

West JB. Thoughts on the pulmonary blood-gas barrier. Am J Physiol Lung Cell Mol Physiol 2003; 285: L501-L513.

Berg JT, Breen EC, Fu Z, et al. Alveolar hypoxia increases gene expression of extracellular matrix proteins and platelet-derived growth factor-B in lung parenchyma. Am J Respir Crit Care Med 1998; 158: 1920-1928.

Kuebler WM, Ying X, Singh B, et al. Pressure is proinflammatory in lung venular capillaries. J Clin Invest 1999; 104: 495-502.

Graça-Souza AV, Arruda MA, de Freitas MS, et al. Neutrophil activation by heme: implications for inflammatory processes. Blood 2002; 99: 4160-4165.

Carpenter TC, Reeves JT, Durmowicz AG. Viral respiratory infection increases susceptibility of young rats to hypoxia-induced pulmonary edema. J Appl Physiol 1998; 84: 1048-1054.

Ono S, Westcott JY, Chang SW, et al. Endotoxin priming followed by high altitude causes pulmonary edema in rats. J Appl Physiol 1993; 74: 1534-1542.

Durmowicz AG, Noordeweir E, Nicholas R, et al. Inflammatory processes may predispose children to high-altitude pulmonary edema. J Pediatr 1997; 130: 838-840.

Das BB, Wolfe RR, Chan KC, et al. High-altitude pulmonary edema in children with underlying cardiopulmonary disorders and pulmonary hypertension living at altitude. Arch Pediatr Adolesc Med 2004; 158: $1170-1176$.

Gabry AL, Ledoux X, Mozziconacci M, et al. High-altitude pulmonary edema at moderate altitude $(<2,400 \mathrm{~m}$; 7,870 feet): a series of 52 patients. Chest 2003; 123: 49-53.

Wodopia R, Ko HS, Billian J, et al. Hypoxia decreases proteins involved in epithelial electrolyte transport in A549 cells and rat lung. Am J Physiol Lung Cell Mol Physiol 2000; 279: L1110-L1119.

Baloğlu $\mathrm{E}, \mathrm{Ke} \mathrm{A}, \mathrm{Abu}-\mathrm{Taha} \mathrm{IH}$, et al. In vitro hypoxia impairs $\beta_{2}$-adrenergic receptor signaling in primary rat alveolar epithelial cells. Am J Physiol Lung Cell Mol Physiol 2009; 296: L500-L509.

Vivona ML, Matthay M, Chabaud MB, et al. Hypoxia reduces alveolar epithelial sodium and fluid transport in rats: reversal by $\beta$-adrenergic agonist treatment. Am J Respir Cell Mol Biol 2001; 25: 554-561.

Nagyova B, O'Neill M, Dorrington KL. Inhibition of active sodium absorption leads to a net liquid secretion into in vivo rabbit lung at two levels of alveolar hypoxia. Br J Anaesth 2001; 87: 897-904.

Egli M, Cook S, Hugli O, et al. Delayed resolution of pulmonary edema in mice with defective sodium transport-dependent alveolar fluid clearance. FASEB J 2001; 15: 860.

Zhou G, Dada LA, Sznajder JI. Regulation of alveolar epithelial function by hypoxia. Eur Respir J 2008; 31: 1107-1113.

Sartori C, Allemann Y, Duplain H, et al. Salmeterol for the prevention of high-altitude pulmonary edema. $N$ Engl J Med 2002; 346: 1631-1636.

Maggiorini M, Brunner-La Rocca HP, Peth S, et al. Both tadalafil and dexamethasone may reduce the incidence of high-altitude pulmonary edema: a randomized trial. Ann Intern Med 2006; 145: 497-506.

Bärtsch P, Mairbäurl H. Salmeterol for the prevention of high-altitude pulmonary edema. N Engl J Med 2002; 347: $1282-1285$.

Bärtsch $\mathrm{P}$, Maggiorini $\mathrm{M}$, Mairbaurl $\mathrm{H}$, et al. Pulmonary extravascular fluid accumulation in climbers. Lancet 2002; 360: 571.

Canouï-Poitrine F, Veerabudun K, Larmignat $\mathrm{P}$, et al. Risk prediction score for severe high altitude illness: a cohort study. PLoS One 2014; 9: e100642.

Richalet JP, Canoui-Poitrine F. Pro: hypoxic cardiopulmonary exercise testing identifies subjects at risk for severe high altitude illnesses. High Alt Med Biol 2014; 15: 315-317.

Bärtsch P. Con: hypoxic cardiopulmonary exercise testing identifies subjects at risk for severe high altitude illnesses. High Alt Med Biol 2014; 15: 318-320.

Hackett PH, Roach RC. High-altitude illness. N Engl J Med 2001; 345: 107-114.

Luks AM, McIntosh SE, Grissom CK, et al. Wilderness Medical Society practice guidelines for the prevention and treatment of acute altitude illness: 2014 update. Wilderness Environ Med 2014; 25: S4-S14.

Hackett PH, Rennie D, Levine HD. The incidence, importance, and prophylaxis of acute mountain sickness Lancet 1976; 2: 1149-1155.

Basnyat B, Lemaster J, Litch JA. Everest or bust: a cross sectional, epidemiological study of acute mountain sickness at 4243 meters in the Himalayas. Aviat Space Environ Med 1999; 70: 867-873.

13: $147-152$.

Beidleman BA, Fulco CS, Muza SR, et al. Effect of six days of staging on physiologic adjustments and acute mountain sickness during ascent to 4300 meters. High Alt Med Biol 2009; 10: 253-260.

Beidleman BA, Muza SR, Fulco CS, et al. Intermittent altitude exposures reduce acute mountain sickness at 4300 m. Clin Sci 2004; 106: 321-328.

Schommer K, Wiesegart N, Menold E, et al. Training in normobaric hypoxia and its effects on acute mountain sickness after rapid ascent to $4559 \mathrm{~m}$. High Alt Med Biol 2010; 11: 19-25.

Fulco CS, Muza SR, Beidleman BA, et al. Effect of repeated normobaric hypoxia exposures during sleep on acute mountain sickness, exercise performance, and sleep during exposure to terrestrial altitude. Am J Physiol Regul Integr Comp Physiol 2011; 300: R428-R436. 
Wille M, Gatterer H, Mairer K, et al. Short-term intermittent hypoxia reduces the severity of acute mountain sickness. Scand J Med Sci Sports 2012; 22: e79-e85.

111 Richalet JP, Bittel J, Herry JP, et al. Use of a hypobaric chamber for pre-acclimatization before climbing Mount Everest. Int J Sports Med 1992; 13: Suppl. 1, S216-S220.

112 Dehnert C, Böhm A, Grigoriev I, et al. Sleeping in moderate hypoxia at home for prevention of acute mountain sickness (AMS): a placebo-controlled, randomized double-blind study. Wilderness Environ Med 2014; 25: 263-271.

113 Roach RC, Maes D, Sandoval D, et al. Exercise exacerbates acute mountain sickness at simulated high altitude. J Appl Physiol 2000; 88: 581-585.

114 Hackett PH. Caffeine at high altitude: java at base cAMP. High Alt Med Biol 2010; 11: 13-17.

115 Aoki VS, Robinson SM. Body hydration and the incidence and severity of acute mountain sickness. $J$ Appl Physiol 1971; 31: 363-367.

116 Castellani JW, Muza SR, Cheuvront SN, et al. Effect of hypohydration and altitude exposure on aerobic exercise performance and acute mountain sickness. J Appl Physiol 2010; 109: 1792-1800.

117 Dumont L, Mardirosoff C, Tramèr MR. Efficacy and harm of pharmacological prevention of acute mountain sickness: quantitative systematic review. BMJ 2000; 321: 267-272.

118 Low EV, Avery AJ, Gupta V, et al. Identifying the lowest effective dose of acetazolamide for the prophylaxis of acute mountain sickness: systematic review and meta-analysis. BMJ 2012; 345: e6779.

119 Kayser B, Hulsebosch R, Bosch F. Low-dose acetylsalicylic acid analog and acetazolamide for prevention of acute mountain sickness. High Alt Med Biol 2008; 9: 15-23.

120 Ellsworth AJ, Larson EB, Strickland D. A randomized trial of dexamethasone and acetazolamide for acute mountain sickness prophylaxis. Am J Med 1987; 83: 1024-1030.

121 Hackett PH, Roach RC, Wood RA, et al. Dexamethasone for prevention and treatment of acute mountain sickness. Aviat Space Environ Med 1988; 59: 950-954.

122 Lipman GS, Kanaan NC, Holck PS, et al. Ibuprofen prevents altitude illness: a randomized controlled trial for prevention of altitude illness with nonsteroidal anti-inflammatories. Ann Emerg Med 2012; 59: 484-490.

123 Zheng CR, Chen GZ, Yu J, et al. Inhaled budesonide and oral dexamethasone prevent acute mountain sickness. Am J Med 2014; 127: 1001-1009.

124 Chen GZ, Zheng CR, Qin J, et al. Inhaled budesonide prevents acute mountain sickness in young Chinese men. J Emerg Med 2015; 48: 197-206.

125 Swenson ER. The lungs in acute mountain sickness: victim, perpetrator, or both? Am J Med 2014; 127: 899-900.

126 Oelz O, Maggiorini M, Ritter M, et al. Prevention and treatment of high altitude pulmonary edema by a calcium channel blocker. Int J Sports Med 1992; 13: Suppl. 1, S65-S68.

127 Broome JR, Stoneham MD, Beeley JM, et al. High altitude headache: treatment with ibuprofen. Aviat Space Environ Med 1994; 65: 19-20.

128 Harris NS, Wenzel RP, Thomas SH. High altitude headache: efficacy of acetaminophen vs. ibuprofen in a randomized, controlled trial. J Emerg Med 2003; 24: 383-387.

129 Grissom CK, Roach RC, Sarnquist FH, et al. Acetazolamide in the treatment of acute mountain sickness: clinical efficacy and effect on gas exchange. Ann Intern Med 1992; 116: 461-465.

130 Levine BD, Yoshimura K, Kobayashi T, et al. Dexamethasone in the treatment of acute mountain sickness N Engl J Med 1989; 321: 1707-1713.

131 Zafren K. Gamow bag for high-altitude cerebral oedema. Lancet 1998; 352: 325-326.

132 Luks AM. Do we have a "best practice" for treating high altitude pulmonary edema? High Alt Med Biol 2008; 9: 111-114.

133 Oelz O, Maggiorini M, Ritter M, et al. Nifedipine for high altitude pulmonary oedema. Lancet 1989; 2: 1241-1244.

134 Fagenholz PJ, Gutman JA, Murray AF, et al. Treatment of high altitude pulmonary edema at $4240 \mathrm{~m}$ in Nepal. High Alt Med Biol 2007; 8: 139-146.

135 Jones BE, Stokes S, McKenzie S, et al. Management of high altitude pulmonary edema in the Himalaya: a review of 56 cases presenting at Pheriche medical aid post $(4240 \mathrm{~m})$. Wilderness Environ Med 2013; 24: 32-36.

136 Singh I, Kapila CC, Khanna PK, et al. High-altitude pulmonary oedema. Lancet 1965; 191: 229-234.

137 Walmsley M. Continuous positive airway pressure as adjunct treatment of acute altitude illness. High Alt Med Biol 2013; 14: 405-407.

138 Dunin-Bell O, Boyle S. Secondary prevention of HAPE in a Mount Everest summiteer. High Alt Med Biol 2009; 10: 293-296.

139 Litch JA, Bishop RA. Reascent following resolution of high altitude pulmonary edema (HAPE). High Alt Med Biol 2001; 2: 53-55 